\title{
MODELING AND SIMULATION OF THE START-UP OPERATION OF A HEAVY-DUTY GAS TURBINE BY USING NARX MODELS
}

\author{
Hamid Asgari $^{1}$, XiaoQi Chen ${ }^{1}$, Raazesh Sainudiin ${ }^{2}$ \\ Mirko Morini ${ }^{3}$, Michele Pinelli ${ }^{4}$, Pier Ruggero Spina ${ }^{4}$, Mauro Venturini ${ }^{4}$ \\ ${ }^{1}$ Department of Mechanical Engineering, University of Canterbury, Christchurch, New Zealand \\ ${ }^{2}$ Department of Mathematics and Statistics, University of Canterbury, Christchurch, New Zealand \\ ${ }^{3}$ Dipartimento di Ingegneria Industriale, Università degli Studi di Parma, Parma, Italy \\ ${ }^{4}$ Dipartimento di Ingegneria, Università degli Studi di Ferrara, Ferrara, Italy
}

\section{ABSTRACT}

In this study, nonlinear autoregressive exogenous (NARX) models of a heavy-duty single-shaft gas turbine (GT) are developed and validated. The GT is a power plant gas turbine (General Electric PG 9351FA) located in Italy.

The data used for model development are three time series data sets of two different maneuvers taken experimentally during the start-up procedure. The resulting NARX models are applied to three other experimental data sets and comparisons are made among four significant outputs of the models and the corresponding measured data.

The results show that NARX models are capable of satisfactory prediction of the GT behavior and can capture system dynamics during start-up operation.

\section{NOMENCLATURE}

$f \quad$ NARX model transfer function

$M \quad$ mass flow rate

$n$ number

$N \quad$ rotational speed

$p \quad$ stagnation pressure

$P_{r C} \quad$ compressor pressure ratio

RMSE root mean square error

$t$ time

$T \quad$ temperature

TIT turbine inlet temperature

TOT turbine outlet temperature

$u \quad$ externally determined input variable

y output variable

\section{Subscripts}

$01 \quad$ compressor inlet section

02 compressor outlet section

04 turbine outlet section

d data set

f fuel

$\begin{array}{ll}\text { in } & \text { inlet } \\ \mathrm{m} & \text { measured } \\ \text { out } & \text { outlet } \\ \mathrm{u} & \text { externally determined input variable } \\ \mathrm{y} & \text { output variable }\end{array}$

\section{INTRODUCTION}

White-box and black-box models are considered as two main categories of gas turbine models respectively based on the fact that information about the physics of the system is enough or not. White-box models usually deal with coupled and complicated dynamic equations, thermodynamic relationships, energy balance, and linearization methods [1]. Black-box models such as nonlinear autoregressive exogenous (NARX) models are employed when access to the complicated dynamic equations of the system is not possible or struggling with them is difficult and undesirable [1]. To set up a reliable black-box model, different kinds of neural networks may be trained based on the values of different parameters of the system for its whole operational range. Before making a decision about the most suitable modeling approach, it is necessary to survey the whole system (in this paper, a gas turbine) including measureable parameters, monitoring system, sensors' health and reliability, system history record, accessibility of the system data, availability of performance curves, technical characteristics. The chosen modeling method should also be compatible with research expectations.

During recent decades, artificial neural networks (ANN) have been widely used for modeling and simulation of industrial systems. ANN, as a data-driven model, is one of the most significant methods in black-box modeling. It has been seen that it can be a very good alternative to conventional approaches for system modeling. It is mainly used to disclose the relationships between variables of the system using the measured operational data from system performance or 
generated data by means of a physics-based model. ANN itself includes different approaches such as nonlinear autoregressive with exogenous inputs (NARX), adaptive network-based fuzzy inference system (ANFIS), feedforward multi-layer perceptron (MLP), nonlinear auto-regressive moving average with exogeneous inputs (NARMAX), backpropagation neural networks (BPNN), radial basis function(RBF), and B-spline.

NARX model as a recurrent neural network has the capability of capturing dynamics of complicated systems such as gas turbines. Such a model can be employed for optimization of design and manufacturing of gas turbines, as well as of the whole operation and maintenance activity of GTs.

Considerable ANN-based models have been built so far for different kinds of gas turbines. The model under investigation can be a micro gas turbine (MGT), an aero gas turbine, or an Industrial Power Plant Gas Turbine (IPGT) including heavyduty industrial gas turbines, which is the subject of this study. In the area of black-box models, specifically constructed for IPGTs, one can refer to the research activities carried out by Lazzaretto and Toffolo [2], Ogaji et al. [3], Arriagada et al. [4], Basso et al. [5], Bettocchi et al. [6-9], Spina and Venturini [10], Simani and Patton [11], Yoru et al. [12], Fast et al. [13-16], Fast and Palme [17] and Fast [18].

As it can be seen from the literature survey, most black-box models have been built based on the steady-state operation of gas turbines, when GTs have already passed the start-up procedures and run in a stable mode. Instead, the literature lacks enough investigations about modeling and simulation of GT start-up procedure. In fact, there is a limited number of studies, directly or indirectly related to modeling of GT start-up procedures. Agrawal and Yunis [19] presented a generalized mathematical model of an aero gas turbine to estimate the engine performance in the starting regime. The model was capable of capturing system dynamics at any ambient temperature or altitude. Balakrishnan and Santhakumar [20] explored the start cycle performance of a typical aero gas turbine engine and the difficulties which may arise in developing a realistic fuzzy model of the engine during the start-up operation. Bianchi et al. [21] built a gas turbine component module library and compared the transient response of an industrial twin-shaft gas turbine to experimental data taken from literature. A comparative analysis of gas turbine engine start-up procedure was carried out by Beyene and Fredlund [22]. Kim et al. [23-25] performed a variety of research activities regarding the transient operation of a combined cycle power plant as well as modeling and simulation of start-up of a heavy-duty gas turbine. Shin et al. [26] analyzed the transient behavior of a combined-cycle power plant using dynamic simulation. In their mathematical model, the authors considered rapid changes and periodic oscillations of the gas turbine load. Steady state and transient aero-thermal models of a micro turbine were explored by Davison and Birk [27]. They presented the results for both acceleration and deceleration of the engine. Huang and Zheng [28] developed a new methodology by combining a stage-stacking method and testing data to calculate the low-speed characteristics of start-up operation for an aero gas turbine. The methodology could be used to estimate the starting characteristics. A novel parsimonious genetic programming (PGP) algorithm and a novel aero-engine optimum data-driven dynamic start process model based on PGP was suggested by Xunkai and Yinghong [29]. The proposed method was useful for modeling complex nonlinear systems by using little prior system knowledge. Cataldi et al. [30] used operational data to model and simulate the start-up of a large-size single-shaft gas turbine. Sanaye and Rezazadeh [31] studied a transient thermal model of heat recovery steam generators in combined cycle power plants. They compared the results from the model to the measured data collected from a cold start-up operation. A transient model of a gas turbine engine was explored by Corbett et al. [32]. Alobaid et al. [33] developed static and dynamic models of a combined cycle power plant and their applications to improve the start-up process of a combined cycle power plant. Transient thermodynamic model of a single-pressure combined cycle power plant under load reduction was investigated by Daneshvar et al. [34]. Sarkar et al. [35] analyzed the time-series data from an aero gas turbine engine and constructed a model for fault detection purposes. Finally, for the same heavy duty gas turbine considered in the current paper, two separate simulation models were developed in [36] by using both a physics-based and a black-box approach. In this case, different maneuvers taken experimentally during transient operation were used for model development and validation.

There are also very useful white-box and black-box methodologies regarding simulation of transient behavior of individual components of gas turbines, such as compressors which can be effectively applied to gas turbines. For instance, one can refer to neural network techniques employed by Venturini [37, 38] to explore transient behavior of compressors. Similar efforts were carried out by Venturini [39] and Morini et al. $[40,41]$ by using white-box methods.

The importance of the start-up procedure of gas turbines and its direct effect on their performance and life time is a strong motivation for researchers to work in this field. There are still many unforeseen events during start-up process which can arise from complicated dynamics of gas turbines. Accurate modeling would require the knowledge of bleed flows and IGV control. Moreover, the operational modes with modern DLN and DLE systems are very complex, also involving fuel splits and bleed action. Since such pieces of information are usually unknown or they are confidential manufacturer's data, the use of a black-box approach allows the implicit incorporation of all these phenomena in a simple simulation model.

Therefore, many research activities should be still carried out to fill the existing information gaps in the literature and to develop such black-box models. On the basis of the literature review performed by the authors on this topic, this paper represents one of the few attempts to develop a dynamic model of the whole gas turbine (and in particular for the start-up maneuver) by means of NARX models and validate it against experimental data taken during normal operation by means of standard measurement sensors and acquisition system. Building 
the required models in this specific area can be very effective in understanding and analyzing gas turbine dynamics, and can also provide information about fault diagnostics.

For this reason, NARX models of the start-up procedure of a heavy-duty gas turbine are constructed in this study. The modeling and simulation are carried out on the basis of the experimental time-series data sets obtained from a GT located in Italy. The results of this modeling approach, which uses as inputs only the variables at antecedent time steps (i.e. no information about the current time step is required), allow the set up of a powerful and easy-to-build simulation tool which can be used for real-time control and sensor diagnostics of gas turbines.

The specifications of the gas turbine are described in the next section. Then, GT start-up procedure, the main steps for data acquisition, data preparation and NARX modeling are discussed. The paper ends up with the results of the comparison of NARX predictions to experimental measurements. Concluding remarks and guidelines are also provided.

\section{GAS TURBINE SPECIFICATIONS}

The gas turbine modeled in this paper is the General Electric PG 9351FA. It is a heavy-duty single-shaft gas turbine used for power generation. The main specifications are summarized in Table 1.

\section{GAS TURBINE START-UP}

The start-up period is the operating period before the gas turbine reaches stable combustion conditions. To start to work, gas turbines need an external source, such as an electrical motor or a diesel engine. GTs use a starter until the engine speed reaches a specific percentage of the design speed. Then, engine can sustain itself without the power of starter. Gas turbine startup procedure can be divided into four phases including dry cranking, purging, light-off and acceleration to idle [30, 42]. In dry cranking phase, the engine shaft is rotated by the starting system without any fuel feeding. In purging phase, residual fuel from previous operation or failed start attempts is purged out of the fuel system. In this phase, the rotating speed is kept constant at a value which ensures a proper mass flow rate through the combustion chamber, the turbine and the heat recovery steam generator.

During light-off, fuel is fed to the combustor, and igniters are energized. This causes ignition to start locally within the combustor, followed by light-around of all the burners. Finally, in acceleration to idle phase, the fuel mass flow rate is further increased and the rotational speed increases towards idle value.

\section{AVAILABLE FIELD DATA}

The data sets used in this study were taken experimentally during several start-up maneuvers and cover the whole operational range of the GT during start-up. Therefore, these data are expected to account for all the conditions related to this type of transient maneuver (e.g. bleed valve opening, IGV control, etc.).
Table 1 - Gas turbine specifications

\begin{tabular}{cc}
\hline GT type & GE $9351 \mathrm{FA}$ \\
Number of shafts & 1 \\
Rotational speed & $3000 \mathrm{rpm}$ \\
Pressure ratio & 15.8 \\
TIT & $1327^{\circ} \mathrm{C}$ \\
TOT & $599^{\circ} \mathrm{C}$ \\
Air flow rate & $648 \mathrm{~kg} / \mathrm{s}$ \\
Power & $259.5 \mathrm{MW}$ \\
Heat rate & $9643 \mathrm{~kJ} / \mathrm{kWh}$ \\
Efficiency & $37.3 \%$ \\
\hline
\end{tabular}

The whole available data sets for the GT can be categorized into three main groups as follows:

o Cold start-up: the gas turbine was shut down some days before the start-up.

o Warm start-up: the gas turbine was shut down some hours before the start-up.

o Hot start-up: the gas turbine was shut down just few hours or less before the start-up.

Moreover, each of the data sets of the above categories may fall into different combinations of the following conditions:

o If the starter is on or off: 1 or 0 ;

o If the gas turbine is connected to the grid or not: 1 or 0 ;

o If customer trip happens or not: 1 or 0 ;

o If the flame is on or off: 1 or 0 .

In this paper, the data sets of cold start-up and the following two maneuvers were considered for developing the simulation models:

o The starter is on: 1 ;

o The gas turbine is connected to the grid or not: 1 or 0 ;

o Customer trip does not happen: 0;

o The flame is on: 1 .

The maneuvers can be classified as [lllllll 1100 or $\left[\begin{array}{llll}1 & 0 & 0 & 1\end{array}\right]$. For instance, [lllllll $\left.1 \begin{array}{lll}1 & 0 & 1\end{array}\right]$ refers to the situation when the starter is on, the gas turbine is connected to the grid, customer trip does not happen, and the flame is on.

The measured time-series data sets which are used for training the NARX models are called TR1, TR2 and TR3. They cover the whole operational range of the gas turbine during the start-up procedure and they all refer to "cold" start-up. The time step for data acquisition is one second.

A combination of TR1, TR2 and TR3 was considered for training, in such a manner that the resulting model can be confidently generalized for GT “cold” start-up simulation. Instead, the data sets TE1, TE2 and TE3 are the data which are employed for test and verification of the resulting models. The Table 2 shows more details about these data and the operational range for the input parameters of the available data sets.

It can be seen that the values of compressor inlet temperature and pressure of the training data sets are different, since they were taken in different seasons during the same year (August, October, December). This choice was made on purpose, with the aim to improve the generalization capability of the NARX models. Moreover, the range of variation of $T_{01}$ 
for TE1, TE2 and TE3 is included in the range of variation of $T_{01}$ of the training data sets.

Figure 1 shows the trends over time of fuel mass flow rate. It can be seen that the trends of all maneuvers are similar, but the rate of change of the rotational speed to reach the fullspeed/no-load condition is different. In particular, TE1 is very close to TR3, while the trend of the fuel flow for TE2 and TE3 lies in the middle between TR1 and TR3.

\section{GT START-UP MODELING BY USING NARX MODELS}

As mentioned, NARX is a nonlinear autoregressive network with exogenous inputs. It has a recurrent dynamic nature and is commonly used in time-series modeling. NARX includes feedback connections enclosing several layers of the network. The defining equation of the NARX model is as follows [43]:

$$
y(t)=f\left[u(t-1), \ldots, u\left(t-n_{\mathrm{u}}\right), y(t-1), \ldots, y\left(t-n_{\mathrm{y}}\right)\right]
$$

where $y$ is the output variable and $u$ is the externally determined variable. The next value of the dependent output signal $y(t)$ is regressed on previous values of the output signal and previous values of an independent (exogenous) input signal.

A NARX model can be implemented by using a feedforward neural network to approximate the function $f$ [43]. NARX models can be used for nonlinear filtering of noisy input signals or prediction of the next value of the input signal.

Table 2 - Experimental time series data sets

\begin{tabular}{ccccc}
\hline \multirow{2}{*}{$\begin{array}{c}\text { Data } \\
\text { set }\end{array}$} & $\begin{array}{c}\text { Number } \\
\text { of data }\end{array}$ & \multicolumn{3}{c}{ Operational range of the inputs } \\
\cline { 3 - 5 } & & $T_{01}[\mathrm{~K}]$ & $p_{01}[\mathrm{kPa}]$ & $M_{\mathrm{f}}[\mathrm{kg} / \mathrm{s}]$ \\
\hline TR1 & 450 & {$[289.8 ; 292.6]$} & {$[101.6 ; 101.9]$} & {$[0.73 ; 4.90]$} \\
TR2 & 362 & {$[281.5 ; 295.9]$} & {$[102.3 ; 102.6]$} & {$[0.98 ; 5.10]$} \\
TR3 & 510 & {$[305.4 ; 308.7]$} & {$[101.6 ; 102.0]$} & {$[0.28 ; 4.80]$} \\
TE1 & 538 & {$[295.9 ; 299.3]$} & {$[100.6 ; 101.0]$} & {$[0.37 ; 4.80]$} \\
TE2 & 408 & {$[299.8 ; 300.9]$} & {$[100.6 ; 101.0]$} & {$[0.49 ; 4.80]$} \\
TE3 & 397 & {$[298.7 ; 299.8]$} & {$[100.6 ; 100.9]$} & {$[0.52 ; 4.80]$} \\
\hline
\end{tabular}

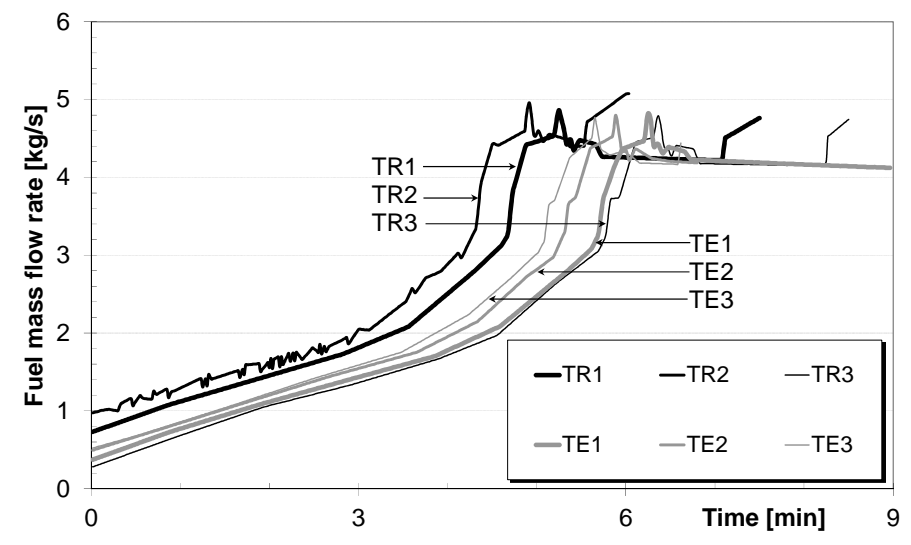

Figure 1 - Trend over time of the fuel mass flow rate
However, the most significant application of NARX networks is to model nonlinear dynamic systems [43].

As it can be noticed from Eq. (1), the NARX models developed in this paper use as inputs only the variables at antecedent time steps. In fact, the exogenous input variable at the current time step $u(t)$ is not an input. This characteristic is remarkable since this modeling approach allows the set up of a software tool which, for instance, may also be used for realtime control optimization and gas turbine sensor diagnostics to be run in parallel with the considered gas turbine.

In this study, the Neural Network Toolbox in MATLAB was employed to build NARX models for a combination of the measured time-series data sets of TR1, TR2 and TR3 in such a manner that the resulting model will cover the whole operational range of the gas turbine start-up operation. The resulting models were obtained after carrying out a thorough sensitivity analysis on NARX parameters (i.e. number of neurons in the hidden layer, number of feedback connections, NARX architecture and number of delayed time points), in order to get as reliable and accurate models as possible in terms of accuracy of the trends and RMSE for the output parameters. At the same time, the structure of the models was kept as simple as possible by considering the minimum required number of neurons and delayed time points. The models were tested against TE1, TE2 and TE3 maneuvers separately.

Figures 2 and 3 show the closed-loop structure of the NARX models and the block diagram of the complete NARX model used for GT simulation, respectively. As Figure 3 shows, the model includes three inputs and four outputs. The input variables $u$ are compressor inlet temperature $T_{01}$, compressor inlet stagnation pressure $p_{01}$, and fuel mass flow rate $M_{\mathrm{f}}$. These quantities were selected, since they are always available, even in poorly instrumented GTs. The output variables $y$ are compressor outlet temperature $T_{02}$, turbine outlet temperature $T_{04}$, compressor pressure ratio $P_{\mathrm{rC}}$ and rotational speed $N$. Figure 3 also shows that the complete NARX model has a multi-input single-output structure, according to [8].

The NARX model for each output parameter was trained separately by using different numbers of neurons in order to get the most accurate prediction. Each model was trained by using the Levenberg-Marquardt backpropagation (trainlm) as the training function, one hidden layer and a tapped delay line with delays from 1 to 2 at the input. In fact, the NARX model with regressed outputs $y(t-1)$ and $y(t-2)$ at time points $(t-1)$ and $(t-2)$ proved to be most accurate solution, by using a lean structure. With regard to the optimal number of neurons in the hidden layer, the best results for all the outputs were obtained by using twelve neurons in the hidden layer.

The parameter used for the comparison of the measured data $y_{\mathrm{m}}$ to the predictions of NARX models, i.e. $y$, is the root mean square error (RMSE) defined according to Eq. (2)

$$
R M S E=\sqrt{\frac{1}{n_{\mathrm{d}}} \sum_{i=1}^{n_{\mathrm{d}}}\left(\frac{y_{m}-y}{y_{m}}\right)^{2}}
$$

where $n_{\mathrm{d}}$ is the number of data of each data set (see Table 2). 


\section{NARX MODEL TRAINING}

The Figure 4 reports the results of the training phase in terms of RMSE. To account for the initial delay of the NARX models to work correctly, the values corresponding to the first ten seconds of each data set are not used for RMSE calculation. The RMSE values slightly depend on the considered training curve, with the exception of $N$ for TR3 (RMSE equal to $12.0 \%)$. The RMSE values for $T_{02}, T_{04}, P_{\mathrm{rC}}$ and $N$ vary in the range $0.7 \%-4.1 \%, 0.8 \%-2.6 \%, 4.6 \%-5.6 \%$ and $3.0 \%-12.0 \%$, respectively. Given that the NARX models are trained with merely three input measurements from experimental data and can generally reproduce the physical behavior, the RMSE values were considered acceptable and the training phase was considered satisfactory.

As a proof that the NARX models are actually capable of reproducing the physical behavior, Figures 5 through 8 show the variations of the four output parameters during the gas turbine start-up process of the maneuvers TR1, TR2, and TR3 for the real system (measured data sets) and the trained NARX models. It should be noted that the training data sets TR1, TR2 and TR3 are supplied as a sequence to the NARX models, as required for the training phase. Instead, the simulation results in Figures 5 through 8 were obtained by simulating these maneuvers one by one. It can be observed that the most significant deviations between measured and simulated values occur during the initial phase of the data sets. This means that the NARX models require a time frame of approximately one minute to stabilize and correctly reproduce the gas turbine behavior (this delay is also clearly highlighted in Figures 10-12 for $T_{04}$ ). Figures 5 through 8 also show that the NARX models can follow the physical behavior when the trend remains almost stationary. Moreover, the NARX models tend to smooth the too rapid variations, as shown in Figure 6 for $T_{04}$.

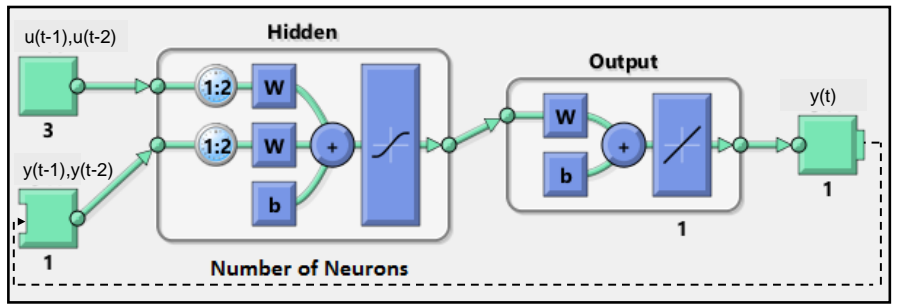

Figure 2 - Closed-loop structure of a single NARX model

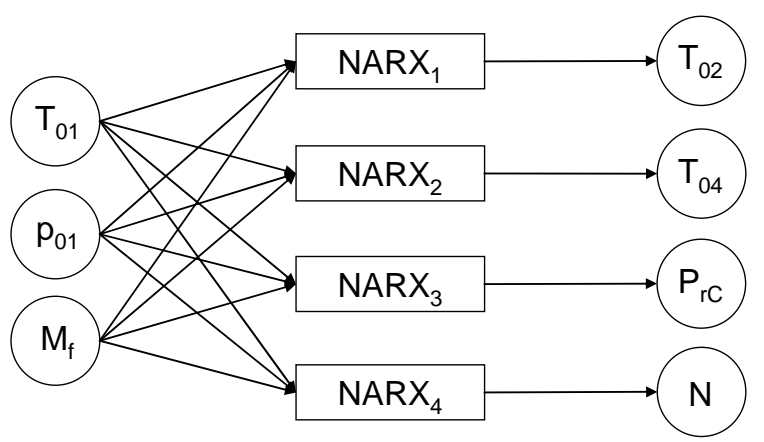

Figure 3 - Block diagram of the complete NARX model
The only noticeable deviation occurs for the pressure ratio in Fig. 7, where the steady-state value is underestimated in all the training curves. In fact, the change of the slope of the pressure ratio curves, which occurs at a rotational speed of about $2600 \mathrm{rpm}$, may not only be due to the increase in the fuel mass flow rate (see Figure 1). In fact, the analysis of the complete data set highlights that a rapid opening of variable inlet guide vanes (VIGVs) also occurs at about $2600 \mathrm{rpm}$. This makes the pressure ratio increase faster, but this phenomenon is not fully grasped by the NARX model since the VIGV angle is not an input of the NARX model. As discussed, this choice was made to build a very lean simulation model.

\section{NARX MODEL VALIDATION}

For validation, the NARX models were tested against three other available experimental time-series data sets which are indexed as TE1, TE2 and TE3. It should be noted that, during the simulation phase, the NARX models are fed with the regressed outputs at time points $y(t-1)$ and $y(t-2)$ estimated by the NARX model itself at antecedent time steps.

The Figure 9 summarizes the results in terms of RMSE for the testing maneuvers. Also in this case, to account for the initial delay of the NARX model to work correctly, the values corresponding to the first ten seconds of each data set are not used for RMSE calculation. A different behavior can be observed for compressor and turbine outlet temperatures, compared to pressure ratio and rotational speed. In fact, RMSE values for temperatures are always lower than approximately $3.5 \%$. Otherwise, the RMSE maximum values of $P_{\mathrm{rC}}$ and $N$ are almost twice (7.4\% for $P_{\mathrm{rC}}$ and $7.1 \%$ for $N$ ). As observed for the training data sets, the RMSE values slightly depend on the considered training curve.

Figures 10 through 12 show the trend-over-time of TE1, TE2 and TE3, respectively. In all cases, the trends of the real system and the NARX models are very similar. This means that the NARX models can follow the changes in GT parameters, even though they are subject to significant changes. In fact, as an example, $N$ is varied from $500 \mathrm{rpm}$ to $3000 \mathrm{rpm}$ in about six minutes and consequently $P_{\mathrm{rC}}$ increases from 1 to about 7 .

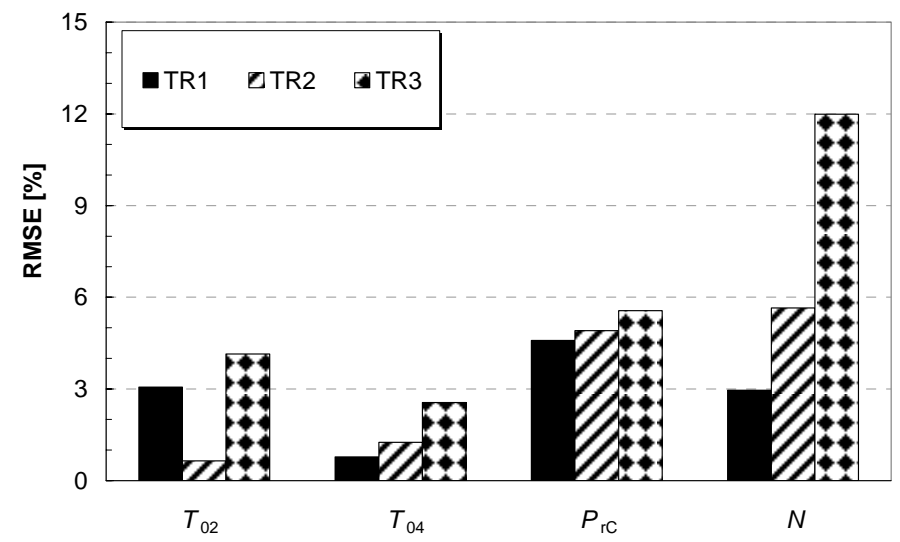

Figure 4 - RMSE of the NARX models for the training maneuvers TR1, TR2 and TR3 

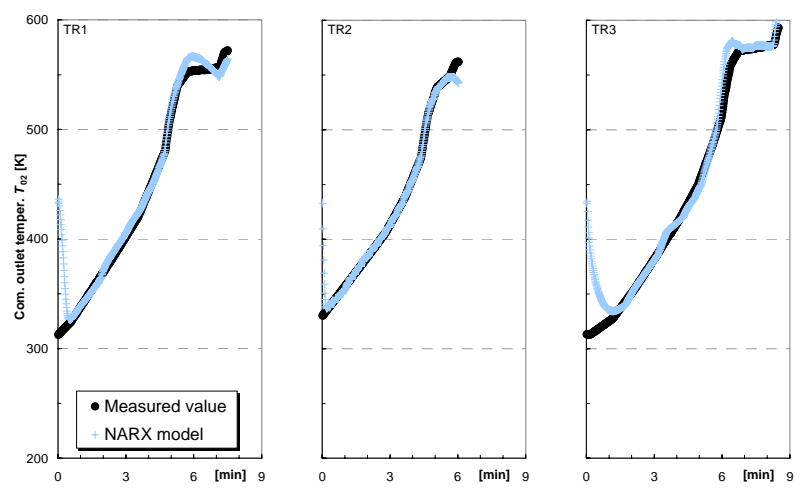

Figure 5 - Variations of compress outlet temperature $T_{02}$ for the training maneuvers TR1, TR2 and TR3
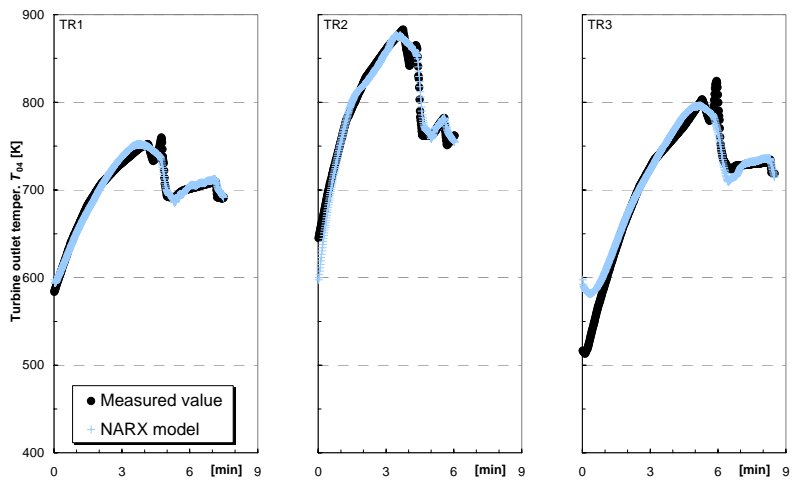

Figure 6 - Variations of turbine outlet temperature $T_{04}$ for the training maneuvers TR1, TR2 and TR3

At the same time, the NARX models can also reproduce less significant changes, as, for instance, can be observed in the trends of turbine outlet temperature $T_{04}$. Finally, the stable operation can also be reproduced very satisfactorily, as it can be clearly seen during the last minutes of each transient maneuver (in particular, in Figure 10). Unfortunately, there are just two cases with a noticeable deviation of the measured and predicted trends, i.e. the compressor pressure ratio $P_{\mathrm{rC}}$ for TE2 and TE3 (see Figures 11 and 12), as already discussed for the training data sets. In any case, as shown above, the overall deviation can still be acceptable. Therefore, it can be concluded that the NARX models reproduced the three testing transients TE1, TE2 and TE3 with a good accuracy.

In conclusion, the results show that the NARX models have the potential to simulate and predict gas turbine dynamic behavior. However, Figures 4 and 9 highlight that general guidelines about the order of magnitude of the errors are difficult to draw, since they may change as a function of the considered maneuver and measurable quantity. Moreover, unfortunately, such deviations cannot usually be minimized contemporarily. The results reported here represent a good compromise on the NARX model prediction capability of the four selected output variables. In fact, the comparison to experimental data was mainly intended to evaluate the
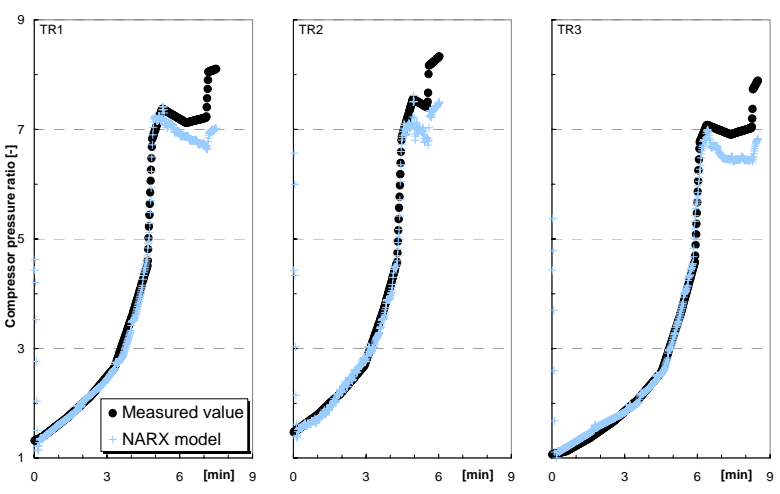

Figure 7 - Variations of compressor pressure ratio $P_{\mathrm{rC}}$ for the training maneuvers TR1, TR2 and TR3
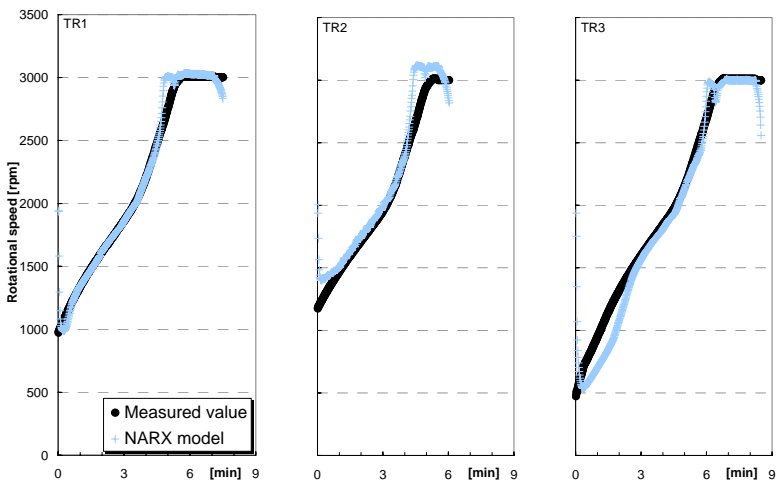

Figure 8 - Variations of rotational speed $N$ for the training maneuvers TR1, TR2 and TR3

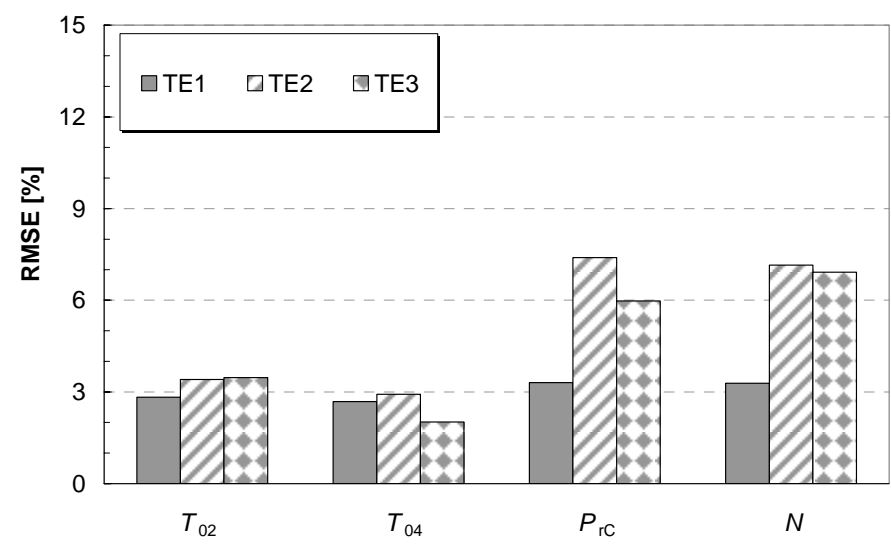

Figure 9 - RMSE of the NARX models for the testing maneuvers TE1, TE2 and TE3

agreement of the trends, rather than the numerical values.

According to the modeling hypotheses made in this study, the structure of the NARX models was kept as simple as possible, so that only three usually available variables were supplied as inputs. Moreover, the differences in the numerical values can also be attributed to the accuracy of the gas turbine experimental measurement system. 

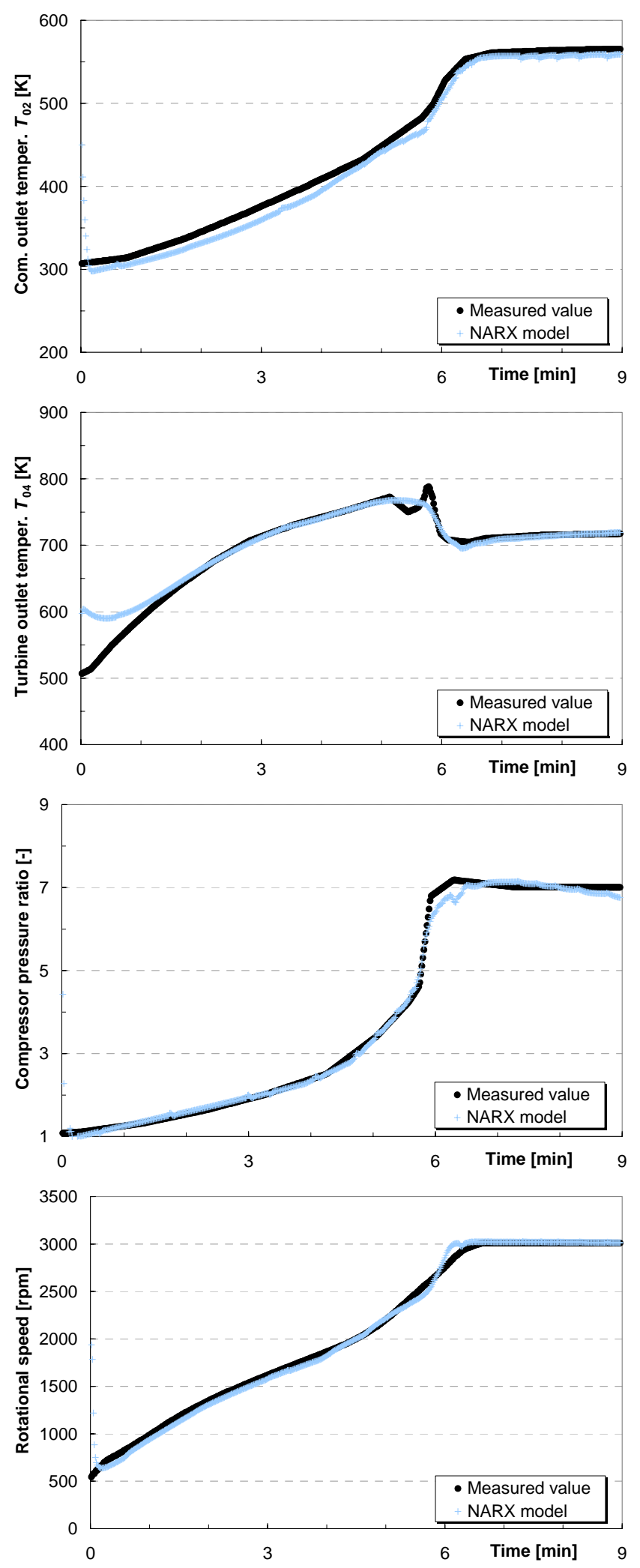

Figure 10 - Variations of compressor outlet temperature $T_{02}$, turbine outlet temperature $T_{04}$, compressor pressure ratio $P_{\mathrm{rC}}$ and rotational speed $N$ for the testing maneuver TE1
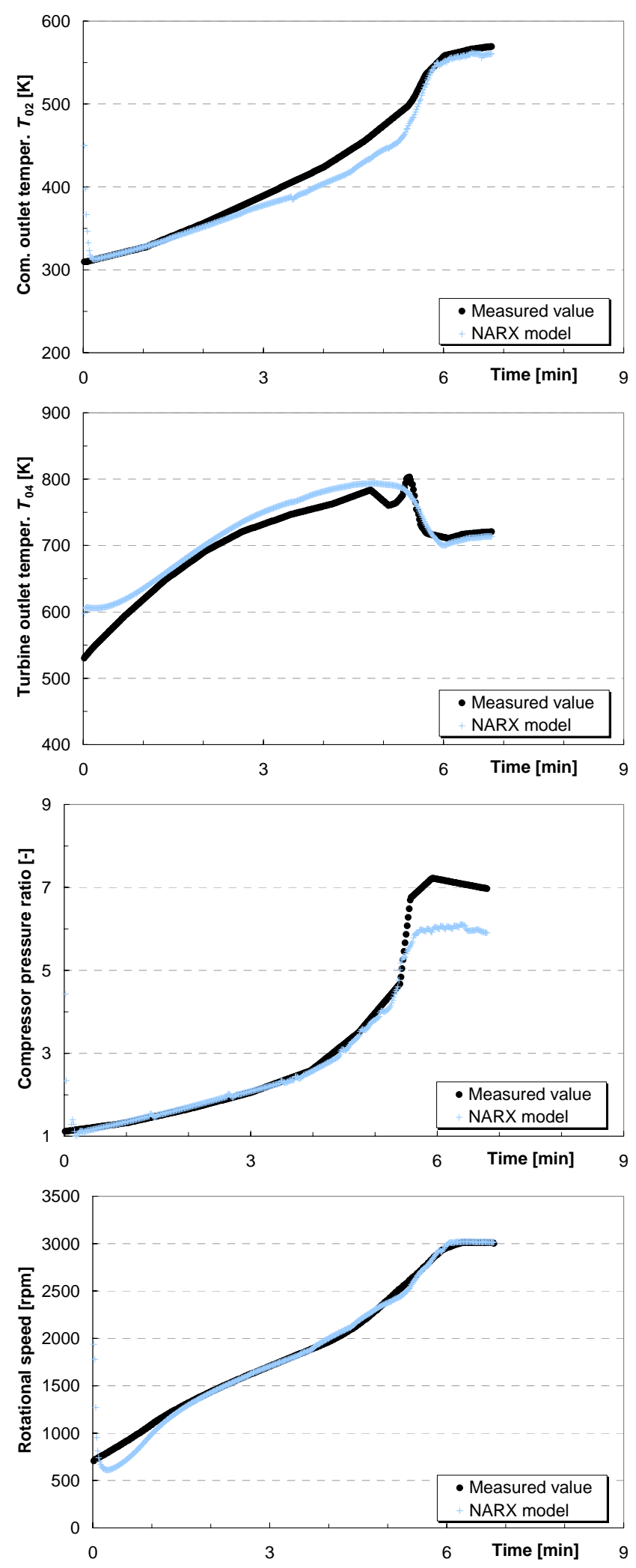

Figure 11 - Variations of compressor outlet temperature $T_{02}$, turbine outlet temperature $T_{04}$, compressor pressure ratio $P_{\mathrm{rC}}$ and rotational speed $N$ for the testing maneuver TE2 

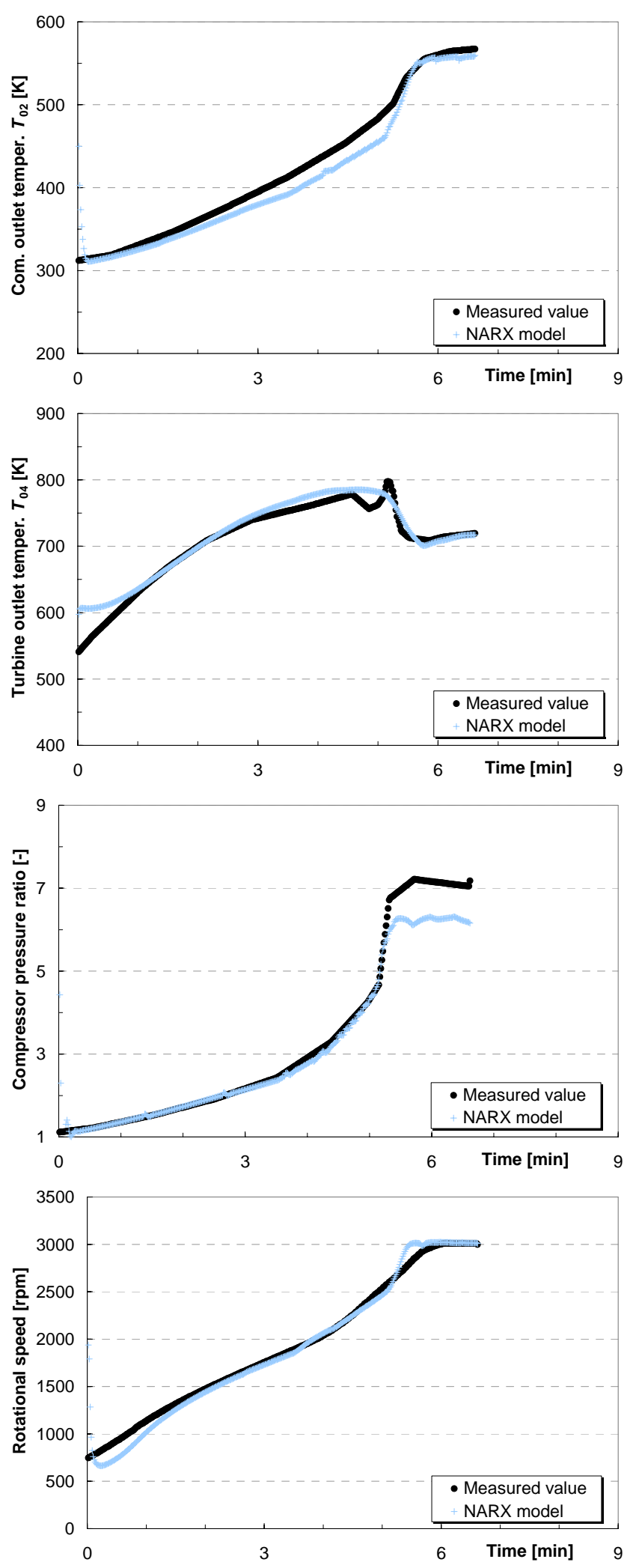

Figure 12 - Variations of compressor outlet temperature $T_{02}$, turbine outlet temperature $T_{04}$, compressor pressure ratio $P_{\mathrm{rC}}$ and rotational speed $N$ for the testing maneuver TE3

\section{CONCLUSIONS}

The main objective of this research was to investigate the dynamic behavior of gas turbines during the start-up phase. For this reason, NARX models of a heavy-duty single-shaft gas turbine were constructed by using three measured time-series data sets. The resulting NARX models were tested against three other available experimental data sets for verification of the models. For this purpose, four important outputs from the models and their corresponding values from the measured data sets were compared, i.e. compressor and turbine outlet temperature, compressor pressure ratio and rotational speed, as a function of compressor inlet temperature and pressure and fuel mass flow rate.

According to the results, the NARX models actually have the capability of capturing and predicting GT dynamics during start-up. In most cases, the deviation between measured and simulated values is acceptable (e.g. lower than approximately $3.5 \%$ for compressor and turbine outlet temperatures), but it can also be considerably higher for compressor pressure ratio and rotational speed (maximum deviations equal to $7.4 \%$ and $7.1 \%$, respectively).

In general, the physical behavior is well grasped by the NARX models (with the exception of the steady state value of compressor pressure ratio) and the influence of the considered data set is negligible.

One of the strong points of this research is the simplicity of the developed NARX models. It is clear that accurate modeling (e.g. through a physics-based approach) does need many pieces of information (e.g. bleed flows and IGV control logic), which can be unknown, confidential manufacturer's data or simply unavailable. For this reason and in order to overcome this lack of information, NARX models were employed as a black-box tool to model the gas turbine for the whole range of start-up operation. The resulting NARX models can reproduce a very complicated and usually difficult-to-model unsteady behavior and can capture system dynamics with acceptable accuracy. It was shown that, in spite of all the controversial issues about the application of neural networks for modeling of industrial systems, they can be considered a reliable alternative to conventional methods in system identification and modeling.

The results of this modeling approach allow the set-up of a powerful and easy-to-build simulation tool which may be used for real-time control and sensor diagnostics of gas turbines. Moreover, the black-box approach to transient analysis may also have the potential to provide diagnostic information for the whole gas turbine.

The future efforts in this area will deal with the investigation of NARX model capability as a multi-step ahead predictor, with the final aim to optimize design, operation and maintenance of gas turbines.

\section{ACKNOWLEDGEMENTS}

This research is supported by Premier Scholarship in Department of Mechanical Engineering at the University of Canterbury (UC), Private Bag 4800, Christchurch 8140, New Zealand. 


\section{REFERENCES}

[1] Jelali M, Kroll A. Hydraulic servo-systems: modeling, identification, and control. Springer Publications; 2004.

[2] Lazzaretto A, Toffolo A. Analytical and neural network models for gas turbine design and off-design simulation. International Journal of Applied Thermodynamics 2001; Vol. 4, No. 4, pp.173-182.

[3] Ogaji S O T, Singh R, Probert S D. Multiple-sensor faultdiagnosis for a 2-shaft stationary gas turbine. Applied Energy2002; Vol. 71, No. 4, pp.321-339.

[4] Arriagada J, Genrup M, Loberg A, Assadi M. Fault diagnosis system for an industrial gas turbine by means of neural networks. In: Proceedings of the International Gas Turbine Congress, Tokyo, Japan; 2003.

[5] Basso M, Giarre L, Groppi S, Zappa G. NARX models of an industrial power plant gas turbine. IEEE Transactions on Control Systems Technology 2004; Vol. 13, No. 4, pp.599-604.

[6] Bettocchi, R., Pinelli, M., Spina, P. R., Venturini, M., Burgio, M., 2004, "Set up of a Robust Neural Network for Gas Turbine Simulation”, ASME Paper GT2004-53421.

[7] Bettocchi, R., Pinelli, M., Spina, P. R., Venturini, M., Zanetta, G. A., 2006, "Assessment of the Robustness of Gas Turbine Diagnostics Tools Based on Neural Networks”, ASME Paper GT2006-90118.

[8] Bettocchi, R., Pinelli, M., Spina, P. R., Venturini, M., 2007, "Artificial Intelligence for the Diagnostics of Gas Turbines. Part I: Neural Network Approach”, ASME J. Eng. Gas Turbines Power, 129(3), pp. 711-719.

[9] Bettocchi, R., Pinelli, M., Spina, P. R., Venturini, M., 2007, "Artificial Intelligence for the Diagnostics of Gas Turbines. Part II: Neuro-Fuzzy Approach”, ASME J. Eng. Gas Turbines Power, 129(3), pp. 720-729.

[10] Spina, P. R., Venturini, M., 2007, “Gas Turbine Modeling by Using Neural Networks Trained on Field Operating Data", Proc. ECOS 2007, June 25 - 28, Padova, Italy, SGE Ed., Padova, Vol. I, pp. 213-222.

[11] Simani S, Patton R J. Fault diagnosis of an industrial gas turbine prototype using a system identification approach. Control Engineering Practice2008; Vol. 16, No. 7, pp.769-786.

[12] Yoru Y, Karakoc T H, Hepbasli A. Application of artificial neural network (ANN) method to exergetic analyses of gas turbines. International Symposium on Heat Transfer in Gas Turbine Systems2009; Antalya, Turkey.

[13] Fast M, Assadi M, De S. Condition based maintenance of gas turbines using simulation data and artificial neural network: A demonstration of feasibility. ASME Turbo Expo, Berlin, Germany; 2008.

[14] Fast M, Assadi M, De S. Development and multi-utility of an ANN model for an industrial gas turbine. Journal of Applied Energy2009; Vol.86, No.1, pp.9-17.

[15] Fast M, Palme T, Genrup M. A novel approach for gas turbines monitoring combining CUSUM technique and artificial neural network. ASME Turbo Expo, Orlando, Florida, USA; 2009.

[16] Fast M, Palme T, Karlsson A. Gas turbines sensor validation through classification with artificial neural networks.
Brazil; ECOS 2009.

[17] Fast M, Palme T. Application of artificial neural network to the condition monitoring and diagnosis of a combined heat and power plant. Journal of Energy 2010; Vol. 35, No. 2, pp.1114-1120.

[18] Fast M. Artificial neural networks for gas turbine monitoring, Doctoral Thesis, Division of Thermal Power Engineering, Department of Energy Sciences, Faculty of Engineering, Lund University, Sweden; 2010.

[19] Agrawal R K, Yunis M. A Generalized Mathematical Model to Estimate Gas Turbine Starting Characteristics. ASME J. Eng. Gas Turbines Power 1982; 104, pp. 194-201.

[20] Balakrishnan SR, Santhakumar S. Fuzzy modeling considerations in an aero gas turbine engine start cycle, FUZZY SETS AND SYSTEMS 1996; Vol. 78, Issue 1, pp.1-4. DOI: 10.1016/0165 0114(95)00195-6.

[21] Bianchi, M., Peretto, A., and Spina, P. R., 1998, "Modular Dynamic Model of Multi-Shaft Gas Turbine and Validation Test," Proc. "The Winter Annual Meeting of ASME,” AES - 38, ASME, New York, pp. 73-81.

[22] Beyene A., Fredlund T., Comparative analysis of gas turbine engine starting. ASME Paper 98-GT-419; 1998.

[23] Kim J H, Song T W, Kim T, Ro S T. Dynamic simulation of full startup procedure of heavy-duty gas turbines. Journal of Engineering for Gas Turbines and Power-Transactions of the ASME 2002; Vol.124, No.3, pp. 510-516.

[24] Kim J H, Song T W, Kim T, Ro S T. Model development and simulation of transient behavior of heavy duty gas turbines. ASME Journal of Engineering for Gas Turbines and PowerTransactions of the ASME 2001; vol.123, No.3, pp.589-594.

[25] Kim T S, Park H J, Ro S T. Characteristics of transient operation of a dual-pressure bottoming system for the combined cycle power plant. Energy 2001; Vol.26, pp. 905-918. [26] Shin J Y, Jeon Y J, Maeng D J, Kim J S, Ro S T. Analysis of the dynamic characteristics of a combined-cycle power plant. Energy 2002, Vol.27, pp.1085-1098.

[27] Davison C R, Birk A M. Steady state and transient modeling of a micro-turbine with comparison to operating engine. In: ASME Turbo Expo: Power for Land, Sea, and Air, Paper No. GT2004-53378; Vol.6, pp.27-35; 2004.

[28] Huang X. H., Zheng X. S., 2005, "Research on startup model of aircraft engine based on stage-stacking method". Acta Aeronautica et Astronautica Sinica 2005; 26(5): 524-528.

[29] Xunkai W, Yinghong L. Aero-engine dynamic start model based on parsimonious genetic programming. In: The Sixth World Congress on Intelligent Control and Automation (WCICA 2006). Vol.1, pp. 1478-1482.

[30] Morini, M., Cataldi, G., Pinelli, M., Venturini, M., 2007, "A Model for the Simulation of Large-Size Single-Shaft Gas Turbine Start-Up Based on Operating Data Fitting”, ASME Paper GT2007-27373.

[31] Sanaye S, Rezazadeh M. Transient thermal modeling of heat recovery steam generators in combined cycle power plants. Int. J. Energy Res. 2007; Vol.31, pp.1047-1063.

[32] Corbett M, Lamm P, Owen P, Phillips S D, Blackwelder M, Alt J T, McNichols J, Boyd M, Wolff J M. Transient turbine 
engine modeling with hardware-in-the-loop power extraction. AIAA Paper 08-5932, 6th International Energy Conversion Engineering Conference (IECEC); 2008.

[33] Alobaid F, Postler R, Strohle J, Epple B, Hyun-Gee K. Modeling and investigation start-up procedures of a combined cycle power plant. Applied Energy 2008; Vol.4, pp.1173-1189.

[34] Daneshvar K, Behbahani-nia A, Khazraii Y, Ghaedi A. Transient modeling of single-pressure combined cycle power plant exposed to load reduction. International Journal of Modeling and Optimization 2012; Vol.2, No.1.

[35] Sarkar Soumalya, Mukherjee K, Sarkar Soumik, Ray A. Symbolic transient time-series analysis for fault detection in aircraft gas turbine engines. American Control Conference (ACC) Book Series: Proceedings of the American Control Conference, pp.5132-5137; 2012.

[36] Asgari, H., Venturini, M., Chen, X., Sainudiin, R., 2014, "Modeling and Simulation of the Transient Behavior of an Industrial Power Plant Gas Turbine”, J. Eng. Gas Turbines Power 136(6), 061601 (10 pages), doi: 10.1115/1.4026215.

[37] Venturini, M., 2006, "Simulation of Compressor Transient Behavior Through Recurrent Neural Network Models”, ASME J. of Turbomachinery, 128(3), pp. 444-454.

[38] Venturini, M., 2007, "Optimization of a Real-Time Simulator Based on Recurrent Neural Networks for Compressor Transient Behavior Prediction”, ASME J. of Turbomachinery, 129(3), pp. 468-478.

[39] Venturini, M., 2005, "Development and Experimental Validation of a Compressor Dynamic Model”, ASME J. of Turbomachinery, 127(3), pp. 599-608. Erratum printed on ASME J. of Turbomachinery, 128(1).

[40] Morini, M., Pinelli, M., Venturini, M., 2007, "Development of a One-Dimensional Modular Dynamic Model for the Simulation of Surge in Compression Systems”, ASME J. of Turbomachinery, 129(3), pp. 437-447.

[41] Morini, M., Pinelli, M., Venturini, M., 2009, “Analysis of Biogas Compression System Dynamics”, Applied Energy, 86, pp. 2466-2475.

[42] Walsh, P P, Fletcher P. Gas turbine performance. Blackwell Science Ltd, UK; 1998.

[43] Hudson Beale M, T Hagan M, B Demuth H. Neural network tool box ${ }^{\mathrm{TM}}$ user's guide, R2011b, The MathWorks, Inc., USA; 2011. 